\title{
ACIMA DE TUDO, QUE A ESCOLA NOS ENSINE.i EM DEFESA DA ESCOLA DE SURDOS
}

\author{
ABOVE ALL, LET THA SCHOOL TEACH US. \\ IN DEFENSE OF THE SCHOOL FOR THE DEAF
}

\section{SOBRE TODO, QUE LA ESCUELA NOS ENSEÑE. EN DEFENSA DE LA ESCUELA DE SORDOS}

\author{
Maura Corcini Lopes ${ }^{1}$; Alfredo Veiga-Neto ${ }^{2}$
}

\begin{abstract}
RESUMO
A luta é condição da existência surda. Em maio de 2011, surdos de todo o Brasil saíram às ruas em defesa da escola de surdos. Foi um movimento sem precedentes em nosso país. Mobilizados, os intelectuais surdos redigiram uma carta ao Ministro da Educação. Em sintonia com seu tempo, eles afirmavam o direito à educação que atendesse às suas especificidades linguísticas e culturais. A mobilização em defesa da escola ocupou as ruas quando era iminente a ameaça do fechamento do Instituto Nacional de Educação de Surdos (INES). Na carta, os surdos concordavam que crianças e jovens com deficiência deveriam estar na escola, mas discordavam que a escola inclusiva fosse o único e melhor espaço para que os alunos aprendessem. Diante dos discursos pró-inclusão, eles afirmavam quererem conviver com os demais cidadãos brasileiros; porém, acima de tudo, queriam que a escola ensinasse. A partir dos Estudos Foucaultianos articulados aos Estudos Surdos em Educação, propõe-se analisar documentos e narrativas surdas em defesa da escola de surdos. Para tanto, parte-se do entendimento da surdez como experiência de subjetivação constituída, entre outros atravessamentos, pela escola e pelos exercícios de liberdade e de convivência surda entre surdos na escola.
\end{abstract}

PALAVRAS-CHAVE Escola. Educação de surdos. Experiência. Movimento surdo.

\section{ABSTRACT}

Struggle has been a condition of the deaf existence. In May 2011, deaf people from all over Brazil took the streets in defense of the deaf school. It was an unprecedented movement in the Brazilian deaf history. Mobilized, deaf intellectuals wrote a letter to the Minister of Education in which the deaf, in tune with their time, stated the right to education that could meet their linguistic and cultural specificities. The mobilization in defense of the school occupied the streets when the National Institute of Deaf Education (INES) was about to be closed. In the letter, the deaf agreed that impaired children and youths should attend school, but disagreed that the inclusive school was the only and the best setting for students to learn. Considering discourses for inclusion, the deaf claimed that they wanted to mingle with other Brazilian citizens; however, above all, they wanted that the school could teach. Grounded on Foucauldian Studies articulated with Deaf Studies in Education, this paper analyzes documents and deaf narratives in defense of the deaf school. Deafness is understood as an experience of subjectivation that is constituted, among other intersections, by the school and the exercises of deaf freedom and living in the school.

KEYWORDS: School. Deaf Education. Experience. Deaf movement.

\footnotetext{
${ }^{1}$ Doutorado em Educação - Universidade Federal do Rio Grande do Sul (UFRGS) - Porto Alegre, RS. Brasil. Graduação em História Natural e Música - Universidade Federal do Rio Grande do Sul (UFRGS) - Porto Alegre, RS. Brasil. Professor - Universidade Federal do Rio Grande do Sul (UFRGS) - Porto Alegre, RS. Brasil. E-mail: alfredoveiganeto@gmail.com.

${ }^{2}$ Doutorada em Educação - Universidade Federal do Rio Grande do Sul (UFRGS) - Porto Alegre, RS. Brasil. Graduação em Educação - Universidade Federal de Santa Maria (UFSM) - Santa Maria, RS - Brasil. Professora Universidade do Vale do Rio dos Sinos (UNISINOS) - São Leopoldo, RS - Brasil. E-mail: maurac@terra.com.br .
}
(C) ETD- Educação Temática Digital
Campinas, SP
v.19
n.4
p. 691-704
out./dez. 2017 


\section{RESUMEN}

La lucha es condición de existencia de los sordos. En mayo de 2011, sordos de todo Brasil salieron a las calles en defensa de la escuela de sordos. Fue un movimiento sin precedentes en la historia de nuestro país. Movilizados, los intelectuales sordos escribieron una carta al Ministro de Educación. En sintonía con su tiempo, ellos afirmaban el derecho a una educación que atendiera sus especificidades lingüísticas y culturales. La movilización en defensa de la escuela ocupó las calles en un momento en que la amenaza de cierre del Instituto Nacional de Educación de Sordos (INES) era inminente. En la carta, los sordos se mostraban de acuerdo en que los niños y jóvenes con deficiencia deberían estar en la escuela, pero rechazaban la idea de que la escuela inclusiva fuera el único y mejor espacio para que los alumnos aprendieran. Frente a los discursos en favor de la inclusión, ellos declaraban su deseo de convivir con los demás ciudadanos brasileros; no obstante, por encima de todo, querían que la escuela enseñase. A partir de los Estudios Foucaultianos articulados con los Estudios Sordos en Educación, se propone analizar documentos y narrativas de los sordos en defensa de la escuela de sordos. Para ello, se parte del entendimiento de la sordera como experiencia de subjetivación constituida, entre otros cruzamientos, por la escuela de sordos y por los ejercicios de libertad y de convivencia entre sordos que en ella tienen lugar.

PALABRAS CLAVE: Escuela. Educación de sordos. Experiencia. Movimiento sordo.

\section{INTRODUÇÃO}

A existência surda só é possível em meio a lutas. Embora esta seja uma constatação central na construção do argumento principal deste artigo, não se tem o objetivo de levantar e analisar os movimentos surdos brasileiros, como muito bem já fizeram, entre outros, Thoma e Klein (2010), Campello e Rezende (2014) e Brito (2013). Tampouco se tem o objetivo de discutir a inclusão e seus efeitos na escolarização e constituição da comunidade surda brasileira. Reconhece-se a importância de tais discussões e parte-se delas para a problematização da escola de surdos como espaço constitutivo de um éthos ou de uma forma de vida surda, conforme escreveram Lopes e Thoma (2013). Além disso, também se parte delas para a argumentação em defesa da escola de surdos.

Para alcançar tal intento, tomam-se ferramentas conceituais foucaultianas que permitem entender regimes de verdade em que estão inscritas as atuais discussões acerca da surdez, dos surdos, da escola e da escolarização de sujeitos surdos. Entre os conceitos utilizados para o desenvolvimento das reflexões aqui construídas, estão o de "matriz de experiência" e o de "subjetivação". Tais conceitos são utilizados por Michel Foucault nos cursos proferidos no Collège de France: "Do governo dos vivos", em 1980; "A hermenêutica do sujeito", em 1982; e "O governo de si e dos outros", em 1983. É a partir daí que se propõe problematizar práticas sobre as quais algumas "verdades" acerca dos indivíduos surdos e de sua escolarização se inscrevem na Contemporaneidade.

É possível afirmar que, naqueles cursos, Foucault, ao deslocar a ênfase dos dispositivos do saber-poder e das tecnologias de dominação para acentuar sua problematização do governo de si pela verdade, dá destacada importância à história da subjetividade. Ocupava o centro das preocupações do filósofo, principalmente nos cursos de 1983 e 1984, o que ele denominou ora como matriz de experiência, ora como núcleo ou

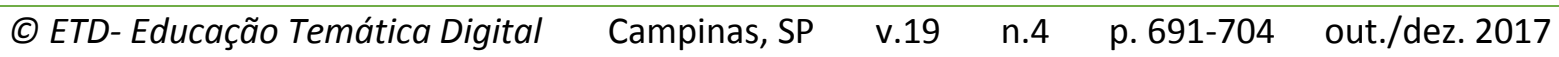


foco de experiência. Sem a preocupação de buscar distinções entre as formas de conceituar utilizadas pelo autor (CASTRO, 2009), interessa para o argumento aqui apresentado mostrar como a surdez pode ser entendida como matriz de experiência (WITCHS, 2014; WITCHS; LOPES, 2015), permitindo a constituição de distintas formas de ser um indivíduo com surdez nos dias de hoje. Nesta linha de argumentação, interessa defender a escola de surdos como espaço de reconhecimento da surdez enquanto superfície sobre a qual se inscrevem experiências visuais. Tais experiências permitem aos surdos operarem, sobre si mesmos, verdades que os subjetivam como pertencentes a um grupo ou a uma comunidade cultural específica. Tal comunidade tem na língua de sinais, na forma de organizar o espaço e o tempo e de reivindicar para si condições dignas de uma vida surda, seus principais indicadores de diferença étnica, de estruturação linguística e de desenvolvimento da aprendizagem.

Para Foucault (2010, p. 41), uma matriz ou um foco de experiência se dá na relação entre três eixos: "o dos saberes; o da normatividade dos comportamentos e os das formas de ser do sujeito". Tomar a própria experiência como objeto de análise é o que permite tensionar a surdez como matriz, pois é sobre tal base que se inscrevem experiências circunscritas em jogos discursivos distintos. Witchs e Lopes (2015, p. 15), ao fazerem o exercício de entender a surdez como matriz de experiências, afirmam que pensá-la dessa maneira permite assumir que, "a partir dela, é possível fazer e dizer coisas sobre determinados indivíduos que a ela são relacionados."

Em entrevista concedida em 1984 a André Scala e Gilles Barbedette, Foucault diz que poderia ser denominado de subjetivação "o processo pelo qual se obtém a constituição de um sujeito, mais exatamente, de uma subjetividade, que evidentemente é apenas uma das possibilidades dadas de organização de uma consciência de si." (FOUCAULT, 2004a, p. 262). Ao estabelecer distinções entre os modos de sujeição e os modos de subjetivação, bem como ao rejeitar a ideia de universalidade do sujeito, o filósofo ressalta as práticas da experiência. As práticas de sujeição, ao partirem de "certo número de regras, de estilos, de convenções que podemos encontrar no meio cultural" (FOUCAULT, 2004b, p. 291), subjetivam os indivíduos. Tais práticas constituem-nos como capazes de articularem sujeição e liberdade em si.

É na articulação entre práticas de sujeição e práticas de liberdade que se entende mais claramente a potência das noções de experiência e de subjetivação para se pensar o sujeito na escola. Não se problematiza qualquer sujeito, mas aquele que toma formas a partir de uma variável constitutiva de sua forma de ser, de conviver, de estar no mundo e de ser regulado por ele: o sujeito surdo. Interessa saber e problematizar as manifestações da verdade sobre a surdez. Manifestações que acontecem em meio a bases epistemológicas e a rituais que apresentam lutas, fracassos e conquistas dos sujeitos denominados surdos e

\begin{tabular}{|c|c|}
\hline - Educacão Temática Diqital & $601-704$ \\
\hline
\end{tabular}


condições não somente para a construção do que se denomina comunidade surda e cultura surda, como também para a produção de saberes sobre os surdos. Dito de outra forma, a produção de saberes sobre os indivíduos surdos fica facilitada quando estes se encontram "disponíveis" e reagem uns com os outros no grupo em que estão colocados.

É do senso comum o fato de que todo ser humano nasce com capacidade de desenvolver a linguagem. Tal desenvolvimento dependerá da convivência com seus pares e da qualidade dos intercâmbios comunicacionais realizados. Quanto mais cedo for a imersão em um dado grupo cultural, melhores serão as condições de desenvolvimento individual. Para Oliver Sacks (2001), a importância de pessoas surdas conviverem com outros surdos está na possibilidade de, o mais cedo possível, desenvolverem a linguagem que lhes é natural, dadas as suas condições sensoriais. Para o neurologista, quanto mais precocemente uma criança surda conviver com outros membros de uma dada comunidade surda, menos restrições haverá em sua vida futura. Nas palavras de Sacks, para as crianças que "nascem surdas, é muito mais fácil adquirir uma linguagem visual como sua primeira língua; e, uma vez dada uma firme fundação nessa linguagem, elas podem aprender a ler e a escrever e, talvez, a falar, ou seja, a tornarem-se bilíngues e biculturais, o que é o ideal para elas." (SACKS, 2001, p. 17).

Embora distintas correntes teóricas sustentem afirmativas diferentes sobre o desenvolvimento da criança surda, predomina o entendimento de que crianças surdas se desenvolvem melhor quando educadas junto a outros surdos. Em outras palavras, partem da defesa da diferença surda, constituída por experiências culturais de fronteira - que ora expulsam, tensionam, homogeneízam e até normalizam a diferença, ora a colonizam e subalternizam, ora a acolhem em um gesto solidário, respeitoso e de profunda sintonia humana.

Embora a noção de cultura de fronteira seja extremamente produtiva para a problematização das práticas surdas, não se tem a intenção de desenvolvê-la neste momento. Desta discussão e para o argumento central que nos conduz à defesa da escola e do ensino de qualidade para surdos, interessa extrair a necessidade de um espaço para que os indivíduos com surdez possam ver-se e constituir-se como surdos, em uma relação de respeito e igualdade de condições.

A história da educação de surdos no Brasil, como é de se esperar, carrega consigo as marcas da Modernidade. Em tal contexto, a escola constitui-se como um tipo de instituição capaz de agir sobre cada indivíduo em particular e sobre o conjunto daqueles que estavam agrupados e submetidos a uma mesma gama de práticas disciplinares. "A educação escolar, a partir da independência, se caracterizava pelas escolas de primeiras letras criadas com o objetivo de ensinar pobres, brancos e livres a ler, escrever e contar." (WITCHS, LOPES,

\begin{tabular}{|c|c|}
\hline - Educacão Temática Diqital & $601-704$ \\
\hline
\end{tabular}


2015a, p. 177). Tais instituições não objetivavam garantir a sequência dos alunos a outros níveis de instrução e eram reguladas pela Lei Geral sobre Instrução Primária, datada de 1827. Em 1856, foi criado o Colégio Nacional para Surdos-Mudos de Ambos os Sexos, no Rio de Janeiro. Tal instituição, ao longo de sua história, foi se configurando de distintas formas e ganhou nomes diferentes ao longo de sua existência. Conforme Rocha (2009), os muitos nomes dados àquele colégio foram: Colégio Nacional para Surdos-Mudos de Ambos os Sexos (1856-1857), Instituto Imperial para Surdos-Mudos de Ambos os Sexos (1857-1858), Imperial Instituto para Surdos-Mudos de Ambos os Sexos (1858-1874), Instituto dos SurdosMudos (1874-1890), Instituto Nacional de Surdos-Mudos (1890-1957) e Instituto Nacional de Educação de Surdos (desde 1957 até hoje). Segundo Witchs e Lopes (2015a), os alunos surdos, para serem matriculados na instituição, "deveriam ter idade entre 7 e 16 anos e certificado de vacinação". Para os autores,

observa-se que os limites da educação de surdos propostos para a criação do instituto brasileiro não se distinguiam da educação oferecida a ouvintes naquele tempo. Além disso, mais do que conteúdos escolares, conforme é possível perceber no contexto europeu e nos objetivos que fizeram esse tipo de educação emergir, a educação de surdos possuía um princípio fundante de reabilitação: tornar o surdo um sujeito capaz de se gerir e ser gerido. Para isso, tornou-se oportuna a relação estabelecida entre Educação e Medicina. (WITCHS; LOPES, 2015a, p. 178)

A partir da entrada dos surdos na escola, algumas variáveis foram "selecionadas" e funcionaram como condições de possibilidade para a emergência de novos saberes clínicos, linguísticos e de ensino de sujeitos com surdez. Os saberes médicos, embora não sendo os únicos em circulação no século $\mathrm{XX}$, eram os mais bem articulados e hegemônicos. Afinados com eles, discursos pedagógicos e linguísticos foram determinantes, fazendo emergir uma forte pedagogia audista de expressão oral.

As práticas audistas na educação e na escola eram justificadas nas observações da capacidade surda de emitir som, de reproduzir palavras faladas e de ter inteligência - o que era demonstrado publicamente pela aprendizagem de conteúdos escolares. Porém, as práticas pedagógicas audistas não eram as únicas a circularem na escola. Outras se configuravam a partir do reconhecimento da capacidade surda de aprender e de desenvolver um sistema linguístico baseado em um tipo de comunicação visual, gestual e espacial. Resumindo, constituíram-se outros entendimentos sobre o desenvolvimento e a aprendizagem dos surdos, junto àqueles audistas de expressão oralista; estes, porém, mantiveram-se na contramão do instituído até o final do século XX.

Retomando rapidamente a história do Colégio Nacional para Surdos-Mudos de Ambos os Sexos (1856-1857) e do Instituto Imperial para Surdos-Mudos de Ambos os Sexos (1858-1874), para explicar parte dos movimentos surdos de resistência à medicalização e à

\begin{tabular}{|c|c|}
\hline (C) ETD- Educação Temática Digital & \\
\hline
\end{tabular}


oralização, é importante apontar a vinda para o Rio de Janeiro de Ernest Huet, professor francês e ex-aluno do Abade de L'Épée, o grande defensor e difusor da comunicação gestual entre surdos.

A proposta trazida por Huet para ser implantada na instituição estava baseada no uso do alfabeto manual da língua francesa de sinais, construído por L'Épée. No espaço do Instituto Imperial, a comunicação gestual era uma constante, mesmo ocorrendo às escondidas ou sendo utilizada em sala de aula, muitas vezes sem o conhecimento oficial de tal prática. A persistência no uso de gestos constituiu um dos mais expressivos movimentos de resistência e de contraconduta da história dos surdos. Com a presença de Huet, os sinais franceses foram misturados aos sinais criados pelos surdos brasileiros para educação daqueles que vinham de diferentes lugares do Brasil.

Ao abordarem-se certos aspectos da institucionalização do encontro e da educação de surdos, não se ignora o fato de que tais sujeitos se encontravam também em espaços fora do ambiente escolar. Vale ressaltar, no entanto, que os espaços abertos eram acessíveis para aqueles surdos mais velhos ou filhos de pais surdos, e não para crianças surdas filhas de pais ouvintes. Surdos filhos de ouvintes dependiam da compreensão dos pais sobre a surdez, geralmente construída a partir de discursos médicos que a descreviam como uma deficiência que poderia ser tratada. O tratamento da surdez dava-se pelo afastamento dos surdos entre si, para que ninguém utilizasse sinais.

A reunião de surdos não teve somente a escola especial e/ou a escola de surdos como espaços possíveis para acontecer. Porém, por meio da escola, tornou-se possível reunir as condições tanto para o desenvolvimento cultural dos indivíduos surdos - desde o mais cedo possível junto a outros surdos -, quanto para a observação do grupo. A escolarização dos surdos com outros surdos acabou produzindo um paradoxo interessante: ao mesmo tempo em que se criavam as condições para o desenvolvimento de um modus vivendi surdo, também se criavam as condições para que os surdos pudessem ser observados como anormais e como usuários de um sistema de comunicação específico e diferente. Tal paradoxo, longe de ser resolvido, convive constituindo distintas práticas divisórias e formas de ser sujeito nas quais os surdos estão imersos.

O Imperial Instituto de Surdos-Mudos do Rio de Janeiro é o que conhecemos hoje por Instituto Nacional de Educação de Surdos (INES), ainda localizado na cidade do Rio de Janeiro e apontado como ícone histórico da cultura surda no Brasil. Sua importância histórica é inegável, principalmente porque ainda hoje funciona como escola e porque guarda arquivos que documentam a história dos surdos e da sua educação, do século XVIII até o presente. Na próxima seção, ao ser abordado o movimento surdo de 2011, retoma-se a importância do INES para os surdos brasileiros.

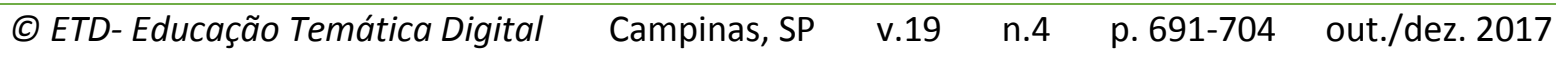




\section{ACONTECIMENTOS PARA PENSAR A ESCOLA DE SURDOS}

Dois grandes eventos podem ser destacados na história dos surdos brasileiros: 0 primeiro ocorreu em 1999, em Porto Alegre; o outro, em 2011, em Brasília. Muitas das reivindicações feitas no primeiro evento parecem ter se mantido no segundo; entre outras: escolas bilíngues para surdos, respeito à diferença surda, qualidade na educação, ensino em Libras e o não fechamento de escolas de surdos. Entre as mudanças nas reivindicações, talvez a maior delas tenha sido a posição surda com relação à inclusão. Em 1999, os surdos afirmavam, categoricamente, ser contra a inclusão. Em 2011, os surdos afirmavam não ser contra a inclusão, mas deixavam claro que queriam promovê-la de outras formas, com mais respeito às suas diferenças linguístico-culturais. Antes de entrar em tais discussões, é importante descrever, mesmo que brevemente, os eventos referidos acima.

Em 1999, aproximadamente 500 surdos reuniram-se em Porto Alegre, no Rio Grande do Sul, por ocasião do Pré-Congresso de Educação de Surdos, ocorrido ao longo de dois dias, antes da realização do III Congresso Latino-Americano de Educação Bilíngue para Surdos. Mais de um ano antes da realização do Congresso, o Núcleo de Pesquisa em Políticas Educacionais para Surdos (NUPPES) da Universidade Federal do Rio Grande do Sul e a Federação Nacional de Integração e Educação de Surdos (FENEIS) investiram na divulgação do evento entre surdos e outros interessados na temática da educação de surdos. Durante o Pré-Congresso, em assembleia, os surdos presentes redigiram um documento contendo as seguintes reivindicações, entre outras: reconhecimento da língua de sinais para o desenvolvimento linguístico, cultural e educacional dos surdos; ampliação do número de escolas de surdos no Brasil; presença de intérpretes de língua de sinais com formação adequada à sua função nas escolas; legendas em programas televisivos; escolas bilíngues para surdos. O documento foi entregue ao governador do Estado do Rio Grande do Sul depois de uma longa passeata pelas ruas de Porto Alegre, com mais de 2.000 pessoas, entre surdos e ouvintes. O documento, devido à sua importância simbólica para a comunidade surda, até hoje é fonte de inspiração para movimentos surdos que ocorrem Brasil afora.

Uma década depois, milhares de surdos reuniram-se em diferentes cidades brasileiras para lutar a favor das escolas de surdos. Tal movimento, sem precedentes históricos, foi resultado de lutas surdas pelo direito a escolas bilíngues de surdos. Campello e Rezende (2014), ao fazerem a história em defesa de uma escola bilíngue de surdos, escreveram que, em 2010, os surdos atuantes na CONAE, ao reagirem ao conteúdo do documento escrito pela equipe da Secretaria de Educação Especial (SEESP/MEC) ${ }^{4}$,

\footnotetext{
${ }^{4}$ A Secretaria de Educação Especial do Ministério da Educação e Cultura foi, posteriormente, absorvida pela Secretaria de Educação Continuada, Alfabetização, Diversidade e Inclusão (SECADI), do Ministério da Educação.
}
(C) ETD- Educação Temática Digital
Campinas, SP
v.19
n.4
p. 691-704
out./dez. 2017 
solicitaram a inclusão de uma emenda ao documento que seria a base para o Projeto de Lei do Plano Nacional de Educação. Conforme as autoras, a reivindicação surda visava a dar

garantia às famílias e aos surdos do direito de optar pela modalidade de ensino mais adequado para o pleno desenvolvimento linguístico, cognitivo, emocional, psíquico, social e cultural de crianças, jovens e adultos, garantindo o acesso à educação bilíngue - utilizando a Língua Brasileira de Sinais (LIBRAS) e a língua portuguesa. (CAMPELLO, REZENDE, 2014, p. 74).

Ainda conforme as autoras, a solicitação de acréscimo à emenda foi negada, sob a justificativa de que frisava a criação de escolas segregacionistas, o que contrariava a concepção de educação inclusiva. A Diretora de Políticas Educacionais Especiais do MEC, Martinha Claret, compareceu ao INES em 17 de março de 2011 "para comunicar ao seu Conselho Diretor, diante da presença de alunos, professores e pais, que o Colégio de Aplicação do INES seria fechado até o final de 2011 e os alunos surdos seriam remanejados para escolas comuns." (CAMPELLO; REZENDE, 2014, p. 75).

A ameaça anunciada pelo Ministério da Educação acabou funcionando como mobilizadora de rituais surdos em defesa de uma forma de ser particular e de poder conviver e mergulhar, o mais cedo possível, em um ambiente linguístico específico, que respeitasse a diferença de desenvolvimento entre surdos e ouvintes. São inúmeros os vídeos em língua de sinais ${ }^{5}$ e os textos públicos contra o fechamento do INES, nos quais os surdos discutem e reivindicam o direito a uma escola de surdos.

Mobilizado por sentimentos de luta e de indignação, um dos líderes surdos, Nelson Pimenta, fez um pronunciamento convocando a comunidade surda a lutar pelos seus direitos. Seu pronunciamento foi traduzido para o português, e na tradução tentou-se resguardar a dor surda diante do extermínio violento de sua história. Mesmo sem referentes fonéticos, o crescimento da dor tomou forma visual de soletração e conseguiu expressar, aos surdos que compartilham de uma cultura de fronteira, a violência a que eles estavam sendo submetidos.

\begin{abstract}
Absurdo! ABSURDO! A-B-S-U-R-D-O! Absurdo de verdade. O quê? O INES fechar!? Calma aí! Não dá pra engolir isso. Não dá. Não, por favor! Por favor, eu imploro. Peço pelo que há de mais sagrado. Parem tudo! Acordem! Divulguem. Fechar o INES, NÃO! Eu quero que vocês surdos pensem bem. Olhem só isso, defendem os surdos! Os surdos vão perder a convivência em língua de sinais, a cultura, a identidade. Perder isso pra sermos oprimidos numa inclusão de ouvintes? NÃO! Abram os olhos! Por favor! Eu peço a vocês: Não vamos deixar essa brutalidade acontecer. Os surdos vão perder a sua cultura. Estou chorando por dentro, meu coração dói. Por favor! Surdos, vamos discutir sobre isso. O MEC não pode mudar o INES. O INES é assim! Não podemos aceitar isso de braços cruzados. Levantem! Lutem! Conto com vocês e fiquem atentos. Nelson Pimenta ${ }^{6}$
\end{abstract}

\footnotetext{
${ }^{5}$ Alguns vídeos considerados nas análises que originaram o presente artigo podem ser vistos na internet nos seguintes endereços: https://goo.gl/cuCFbv.

6 Tradução da língua de sinais para a língua portuguesa (legenda do vídeo). Disponível em: www.youtube.com/watch?v= yl6cfWmUrtU. Acesso em 30 mar. 2017.
}

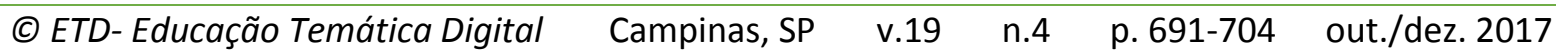


A luta é histórica e constitui-se numa marca da cultura surda (LOPES; VEIGA-NETO, 2006). Quando não se nasce em um território surdo, quando não se é filho de surdos para poder compartilhar de uma língua visual e gestual desde o mais cedo possível, depositam-se na escola de surdos as expectativas da renovação cultural, além da esperança de compreender os acontecimentos de um mundo naturalizado como construído para a maioria ouvinte.

A defesa do INES, portanto, é simbólica não só porque se trata de mais uma escola que está ameaçada de fechar, mas porque se entende tal fechamento como extermínio étnico. Usar a expressão "extermínio étnico" de forma articulada ao espaço físico da escola pode induzir a pensar na defesa de uma escola como gueto surdo. De maneira alguma o já referido movimento surdo de 2011 apoiaria tal entendimento. Os surdos faziam questão de afirmar serem a favor da inclusão e de dar condições aos sujeitos de estabelecerem as relações vividas tanto dentro do espaço surdo quanto fora dele. Em carta aberta, escrita por Ana Regina Campello, Gládis Perlin, Karin Strobel, Marianne Stumpf, Patrícia Rezende, Rodrigo Marques e Wilson Miranda (2011) - todos doutores surdos em Educação e em Linguística - e entregue ao Ministro da Educação em 2011, está escrito:

[...] Nós, surdos, militantes das causas dos nossos compatriotas surdos, apelamos a Vossa Excelência pelo nosso direito de escolha da educação que melhor atende aos surdos brasileiros que têm a Libras como primeira língua. Concordamos que "O Brasil tem que ter $100 \%$ das crianças e jovens com deficiência na escola", sim, mas não concordamos que a escola regular inclusiva seja o único e nem o melhor espaço onde todas essas crianças e jovens conseguem aprender com qualidade. Afirmar que 'A política de educação inclusiva permitiu um crescimento espetacular, de forma que os estudantes com deficiência convivem com os outros alunos e os outros alunos convivem com eles' nos angustia, pois queremos conviver com os demais cidadãos brasileiros, sim, mas queremos, acima de tudo, que a escola nos ensine.

Como sujeitos de seu tempo, a luta é pelo direito de conviverem com outros surdos, de terem acesso à língua e à cultura surda desde o mais cedo possível e, fundamentalmente, de serem educados e conduzidos pedagogicamente para a aprendizagem em um ambiente que priorize o acesso ao conhecimento, e não somente ao domínio de uma língua oral que necessita ser memorizada. A aposta surda é no sujeito surdo e, acima de tudo, na aprendizagem proporcionada pela escola de surdos. Eles querem uma escola que, acima de tudo, ensine. Para tanto, ter uma língua desenvolvida para que aquilo que é ensinado seja aprendido, significado e assimilado, servindo de base para novos conhecimentos, é condição fundamental que vem sendo possibilitada pela escola de surdos. Na sequência da carta referida anteriormente, lê-se: 
Sem dúvida, ter a escola como primeiro espaço de construção de uma cultura surda implica movimentos constantes de lutas pela sua manutenção como espaço de surdos; mas implica, também, retomar constantemente as razões pelas quais se envia qualquer criança à escola. Diante de tal imbricamento entre vida surda, cultura, escola e pedagogia, torna-se fundamental a retomada constante da escola como espaço público. Um espaço onde o "conhecimento, por exemplo, mas também as habilidades que têm uma função especial na sociedade são tornados gratuitos e disponíveis para o uso público." (MASSCHELEIN, SIMONS, 2013, p. 39).

Defender a escola como espaço de estudo e de acesso público ao conhecimento não descarta defendê-la também como espaço de luta e de defesa de uma identidade surda. Identidade surda que, na grande maioria das vezes, é formada na escola a partir do que Wiewiorka (2002) denomina de processo de "inversão de estigma". Dito de outra forma, os alunos chegam à escola como deficientes, aguardando ser acompanhados por especialistas da educação especial. Estando na escola de surdos, de maneira intencional, uma inversão é operada, ou seja, os surdos são conduzidos a se verem e a se pensarem como integrantes de um grupo cultural específico. Operar tal inversão não é a única função da escola; somam-se a ela o compromisso ético e moral com a disciplina e o acesso sistematizado ao conhecimento historicamente construído.

Embora Masschelein e Simons (2014) não conduzam a argumentação em defesa de um tipo ou outro de escola, eles possibilitam pensá-la como espaço público de igualdade, de exercício - de uns sobre os outros e de cada um sobre si mesmo - e de liberdade. Ao pensá-la dessa maneira, percebe-se o quão fundamental é ter, como condição de partida para a educação dos escolares, uma língua que possibilite a todos compartilhar códigos e conhecimentos, ter experiências de uso do tempo e viver os medos e as angústias comuns.

Diante de tais entendimentos, defender a escola como escola, e não como espaço de colonização - seja ela de ordem cultural, social e/ou econômica de uns sobre outros -, não implica aceitar para os surdos a mesma escola para onde vão alunos ouvintes que desde o nascimento se encontram imersos em um ambiente linguístico que respeita sua condição. Também não implica ser a favor de uma escola especial para surdos, pois esta partirá do princípio da deficiência e da segregação dos alunos surdos. Defende-se aqui uma escola de surdos capaz de conduzir aqueles que a buscam para se desenvolverem e se apropriarem dos conhecimentos escolares em condições de igualdade de comunicação. Defende-se uma escola de surdos capaz de fortalecer laços humanos entre semelhantes que compartilham uma forma de vida construída sob um éthos surdo. 


\section{REFERÊNCIAS}

BRITO, Fabio Bezerra de. O movimento social surdo e a campanha pela oficialização da língua brasileira de sinais. 2013. Tese. (Doutorado em Educação) - Programa de PósGraduação em Educação, Universidade de São Paulo. São Paulo, SP: 2013.

CAMPELLO, Ana Regina; REZENDE, Patrícia Luiza Ferreira. Em defesa da escola bilíngue para surdos: a história de lutas do movimento surdo brasileiro. Educar em Revista, Curitiba, n. 2, 2014. Disponível em: https://goo.gl/d5aE5q. Acesso em 15 set. 2017

CASTRO, Edgardo. Vocabulário Foucault. Belo Horizonte, MG: Autêntica, 2009. 478 p. ISBN 9788575264027.

DAVIS, Lennard. Enforcing normalcy: disability, deafness, and the body. London; New York: Verso, 1995. 203 p. ISBN 1859849121

FOUCAULT, Michel. O retorno da moral. In: FOUCAULT, Michel. Ditos e escritos V. Rio de Janeiro, RJ: Forense universitária, 2004a. 322 p. ISBN 8521803247.

FOUCAULT, Michel. A hermenêutica do sujeito. São Paulo, SP: Martins Fontes, 2004b. 680 p. ISBN 8533619952

FOUCAULT, Michel. $O$ governo de si e dos outros. São Paulo, SP: WMF Martins Fontes, 2010. 380 p. ISBN 9788578273217

LOPES, Maura Corcini; MORGENSTERN, Juliane Marschall. Inclusão como matriz de experiência. Pro-posições, São Paulo, SP. v. 25, n. 2 (74), 2014. Disponível em: https://goo.gl/ww7Tws. Acesso em 15 set. 2017

LOPES, Maura Corcini; THOMA, Adriana da Silva. Subjectivation, normalisation et constitution de l'éthos sourd: politiques publiques et paradoxes contemporains. La nouvelle revue de l'adaptation et de la scolarisation, n. 64. Paris, 2013. Disponível em: https://goo.gl/M4GLon. Acesso em: 15 set. 2017.

LOPES, Maura Corcini; VEIGA-NETO, Alfredo. Marcadores culturais surdos: quando eles se constituem no espaço escolar. Perspectiva, v. 24, n. especial. Florianópolis, SC: 2006. Disponível em: https://goo.gl/FKXimM. Acesso em 15 set. 2017.

MASSCHELEIN, Jan; SIMONS, Maarten. A pedagogia, a democracia, a escola. Belo Horizonte, MG: Autêntica, 2014. 237 p. ISBN 9788582172100

MASSCHELEIN, Jan; SIMONS, Maarten. Em defesa da escola. Uma questão política.Belo Horizonte, MG: Autêntica, 2013. 174 p. ISBN 9788582172520 
ROCHA, Solange Maria da. Antíteses, díades, dicotomias no jogo entre memória e apagamento presentes nas narrativas da história da educação de surdos: um olhar para o Instituto Nacional de Educação de Surdos (1856/1961). 2009. Tese (Doutorado em Educação) - Programa de Pós-Graduação em Educação, Pontifícia Universidade Católica do Rio de Janeiro. Rio de Janeiro, RJ: 2009.

SACKS, Oliver. Apresentação. In: CAPOVILLA, Fernando César; RAPHAEL, Walkiria. Dicionário enciclopédico ilustrado trilíngüe da Língua de Sinais Brasileira. São Paulo, SP: 2001. 833 p. ISBN8531406684

THOMA, Adriana da Silva; KLEIN, Madalena. Experiências educacionais, movimentos e lutas surdas como condições de possibilidade para uma educação de surdos no Brasil. Cadernos de Educação. v. 1, n. 36. Pelotas, RS: 2010. Disponível em: https://goo.gl/iipkDj. Acesso em: 15 set. 2017.

WIEVIORKA, Michel. A diferença. 1. ed. Lisboa: FENDA, 2002. 241 p. ISBN 9728529821

WITCHS, Pedro Henrique; LOPES, Maura Corcini. Educação de surdos e governamentalidade linguística no Estado Novo (Brasil, 1934-1948). História da Educação, v. 19, n. 47. Porto Alegre, RS: 2015. Disponível em: https://goo.gl/5mFkDW. Acesso em: 15 set. 2017.

WITCHS, Pedro Henrique; LOPES, Maura Corcini. Surdez como matriz de experiência. Revista Espaço. v. 43, n. 43. Rio de Janeiro, RJ. Disponível em: https://goo.gl/nazHFz. Acesso em: 15 set, 2017.

WITCHS, Pedro Henrique. A educação de surdos no Estado Novo: práticas que constituem uma brasilidade surda. 2014. Dissertação (Mestrado em Educação) - Programa de PósGraduação em Educação, Universidade do Vale do Rio dos Sinos (UNISINOS). São Leopoldo, RS: 2014.

\footnotetext{
' Revisão gramatical do texto sob a responsabilidade dos autores.
} 